\title{
Design and Development of a Web-based 3D Cadastral
}

\author{
Visualisation Prototype
}

\author{
Davood Shojaei*, Abbas Rajabifard, Mohsen Kalantari, Ian D. Bishop and Ali Aien \\ Centre for Spatial Data Infrastructures and Land Administration, Department of Infrastructure Engineering \\ The University of Melbourne, Victoria 3010, Australia \\ (shojaeid, abbas.r, saeidks, i.bishop, aiena)@unimelb.edu.au \\ *Corresponding author.
}

\section{Abstract}

Three-dimensional developments of land, such as complex high-rises, put enormous pressure on current land administration systems that have ad hoc approaches to 3D property management. These approaches are unable to support effective 3D storage, analysis, and visualisation of property information. Effective visualisation is one of the essential components in realisation of a truly 3D cadastre. Currently, several 3D visualisation applications and cadastral prototypes have been developed around the world. However, they do not effectively represent ownership information in 3D because they have not been developed based on 3D cadastral visualisation requirements. After candidate 3D visualisation solutions were compared with user-derived visualisation criteria, a web-based 3D visualisation prototype was designed and developed. The functionality, usability and efficiency of the prototype were evaluated by potential users involved in the registration and management of property. While there was a high level of enthusiasm for the features of the prototype, the results also suggest further directions for development of 3D cadastral visualisation.

Keywords: 3D visualisation, 3D cadastre, WebGL, legal objects, physical objects, 3D cadastral visualisation.

\section{Introduction}

Population growth and lack of available land particularly in the dense urban areas have caused rapid developments both above and below the ground. Overlapped and interlocked land and property interests (3D property) are the results of this trend. A 3D property (legal object) is a real property that is legally delimited both vertically and horizontally (Paulsson and Paasch, 2011). Management and registration of 3D properties are among the most important challenges to current land administration systems, which are equipped with 
cadastres that are used primarily to maintain 2D spatial data (van Oosterom, 2013, Aien et al., 2013a).

Three dimensional (3D) cadastres would assist management and registration of 3D properties. A 3D cadastre should be capable of storing, manipulating, querying, analysing, updating, and visualising 3D properties. Hence, development of a successful 3D cadastre requires consideration of various legal, institutional and technical aspects (Aien et al., 2011).

From the technical perspective, different topics such as 3D data acquisition, 3D database management systems, and 3D data modelling are considered in the development of a 3D cadastral application. However, 3D visualisation also plays a significant role in development of a successful 3D cadastral application (Shojaei et al., 2013). A 3D cadastral visualisation application facilitates communication and exploration of 3D properties using visualisation techniques in a 3D space. The visualisation component is the point at which most end users will encounter a 3D cadastre. While it is possible to imagine a 3D cadastre without a visualisation component, this would probably be limited to a few highly specialised users. If the cadastre is to realise its potential, it needs a visualisation component that is accessible to many disparate users. In addition, due to progress in technology, web-based visualisation applications are popular among end users as they are easily accessible.

Several web-based visualisation prototypes/applications have been developed for representing land ownership boundaries in 3D (Dimovski et al., 2011, Aditya et al., 2011, Guo et al., 2011, Vandysheva et al., 2012, Elizarova et al., 2012, Shojaei et al., 2012, Ying et al., 2012, Lemmen et al., 2010, Stoter, 2004, Coors, 2003, Stoter and Salzmann, 2003). Various solutions have been utilised in these prototypes/applications. However, each of them has some significant limitations.

\subsection{Problem Description}

Since the concept of 3D cadastre emerged, numerous prototype applications have been developed (Stoter and Zlatanova, 2003, Jarroush and Even-Tzur, 2004, Hassan and Abdul Rahman, 2010, Frédéricque et al., 2011). However, as yet there is no 3D cadastral visualisation application implemented anywhere in the world that can support all the 3D cadastral visualisation requirements. Thus, research on 3D cadastral visualisation needs more investigation (Pouliot, 2011, van Oosterom, 2013, Van Oosterom, 2012). For example, applications built using Google Earth do not represent underground objects. Also, a cross- 
section view, which facilitates understanding of the ownership boundaries, is not available in many $3 \mathrm{D}$ visualisation prototypes.

\subsection{Aim, scope and delimitation}

This paper describes the design and development of a 3D cadastral visualisation prototype based on all the requirements of 3D cadastres that have been identified previously (Shojaei et al., 2013). We focused on 3D cadastre implementation, as a significant gap is evident in 3D visualisation of cadastre. According to the literature, despite the activities in 3D cadastral prototype developments, there are many steps of validation which are required before these may be considered as real 3D cadastral visualisation applications (Pouliot, 2011). Other authors recognised the need for further research in this area (Pouliot, 2011, van Oosterom, 2013, Van Oosterom, 2012).

Streaming and visualising 3D data maintained in a DBMS are important subjects in 3D cadastre application developments, however, in this paper, we investigated how to visualise cadastral 3D data associated with individual buildings. This challenge is more related to user-interface development. Therefore, data sources can be in any format or streamed from a DBMS. Findings on visualising individual buildings can be utilised for future application developments by considering other aspects such as city scale, data formats, data exchange formats, and streaming from a database.

We begin with a review of current 3D visualisation solutions and cadastral prototypes. However, as web-based solutions have been identified as an important visualisation requirement among end users such as the public, land surveyors, developers, architects and registrars (Shojaei et al., 2013), only web-based 3D visualisation applications, and not desktop solutions, are reviewed in this paper. In addition, this paper focuses only on 3D visualisation and we do not look at data management or data delivery.

\subsection{Methodology}

The development of our 3D cadastral visualisation prototype had four stages:

- Review of the requirements of 3D cadastral visualisation applications as identified and validated in Shojaei et al. (2013) (Section2);

- Review, against requirements, of 3D web-based visualisation solutions and choice of a preferred option (Section3); 
- Evaluation of the developed prototype by different end users such as land registry, local councils, and surveyors (Section5).

\section{Review of 3D Cadastral Visualisation Requirements}

A comprehensive set of requirements for 3D cadastral visualisation was identified by Shojaei et al. (2013). These requirements were grouped into three main categories: cadastral requirements, visualisation requirements and non-functional requirements (Table 1).

Cadastral requirements are essential elements in developing efficient and effective cadastral applications to represent 3D properties. Visualisation requirements are a set of features that are widely used in general 3D visualisation applications to facilitate communication with end users. Non-functional requirements provide support for technical diversity, system interoperability and integration and usability.

Table 1. The list of 3D cadastral visualisation requirements (Shojaei et al., 2013).

\begin{tabular}{|c|c|c|}
\hline Features & Visualisation Requirements & Description \\
\hline \multirow{6}{*}{ Cadastral Features } & Handling Massive Data & $\begin{array}{l}\text { Representing massive cadastral data using } \\
\text { visualisation techniques }\end{array}$ \\
\hline & Result of Functions and Queries & $\begin{array}{l}\text { Visualising the results of cadastral functions } \\
\text { and queries }\end{array}$ \\
\hline & Underground View & Representing objects beneath ground level \\
\hline & Cross-section View & Slicing an object at a plane \\
\hline & Measurements (3D) & Measuring unofficial distances or areas \\
\hline & Display non-Spatial Data & $\begin{array}{l}\text { Illustrating legal documents attached to each } \\
\text { development }\end{array}$ \\
\hline \multirow{7}{*}{$\begin{array}{l}\text { Visualisation } \\
\text { Features }\end{array}$} & Interactivity & Required tools for exploring a 3D scene \\
\hline & Levels of Detail & $\begin{array}{l}\text { Visualisation technique for accelerating the } \\
\text { rendering process }\end{array}$ \\
\hline & Symbols & Cartographical elements \\
\hline & Colour, Thickness, Line-Style & Object properties for visualisation of data \\
\hline & Labelling & Annotations attached to objects on a scene \\
\hline & Transparency & Object properties for visualisation of data \\
\hline & Tooltips & An identify tool to presents attribute data \\
\hline \multirow{6}{*}{$\begin{array}{l}\text { Non-Functional } \\
\text { Features }\end{array}$} & Technical Diversity & Diversity in supported technology \\
\hline & System Integration and Interoperability & $\begin{array}{l}\text { The ability to exchange data and connect } \\
\text { different components of applications }\end{array}$ \\
\hline & Usability & Ease of use and learnability \\
\hline & Platform Independence & Independence from a specific platform \\
\hline & Cost & $\begin{array}{l}\text { Cost of developing and maintenance a } \\
\text { visualisation application }\end{array}$ \\
\hline & Web-based 3D Visualisation & Web-based solution \\
\hline
\end{tabular}


Various 3D web-based visualisation solutions were evaluated against these requirements as described in the next Section.

\section{Review of Common 3D Web-based Visualisation Solutions}

110 In this section various 3D web-based visualisation solutions are reviewed and compared in

111 order to choose a suitable option for prototype development.

\section{$112 \quad 3.1 \quad$ Candidate Solutions}

113 We selected for review several web-based 3D visualisation solutions which have been

114 developed for various applications. The selection was based on availability to the authors,

115 cost, user-friendliness and development environment. They were then analysed for their 116 capability for visualising 3D cadastral data.

\subsubsection{WebGL Technology}

WebGL is a new technology, royalty-free web standard based on OpenGL 119 (www.khronos.org/webgl) and provides users with 3D models using canvas elements, 120 container for graphics, in HTML 5. WebGL brings plug-in-free 3D to the web and major browsers. WebGL is discussed further in Section 3.2.

\subsubsection{Google Earth}

Google Earth is a popular 3D visualisation application. The Google Earth Plug-in and its 124 JavaScript API enables embedding Google Earth in web pages. Also, the API is able to load $1253 \mathrm{D}$ models in KML/KMZ formats which allows sophisticated 3D applications. For example, 126 Trias, et al. (2011) chose Google Earth API as a visualisation interface for representing 3D cadastral information. Also, Shojaei et al. (2012) used Google Earth API for representing LandXML/ePlan files. Google Earth is able to visualise 3D city models with high resolution satellite/aerial images. However, Google Earth fails to represent underground objects, such as tunnels or easement rights, which are very important in cadastres.

\subsubsection{NASA World Wind}

NASA World Wind (worldwind.arc.nasa.gov/java) is a geographic information application and fully 3D interactive globe developed by NASA Ames Research Center. It provides satellite imagery and a terrain model for the Earth. Java developers are able to integrate this into their web pages or use it as a stand-alone application for various purposes. This 
136 visualisation application is standard-based, open-source technology and works on cross-

137 platforms. For instance, Dimovski, et al. (2011) have utilised NASA World Wind to

138 implement an operational web-based 3D cadastral visualisation application based on the

139 needs of the Agency for Real Estate Cadastre of the Republic of Macedonia. This application

140 appears simple to operate and meets a number of important requirements, but fails our test

141 because of the inability of World Wind to show physical or legal entities that are under the 142 ground surface.

\subsubsection{BS Contact}

144 BS Contact (www.bitmanagement.com) is a web-based viewer which provides full 145 interactivity for 3D visualisation on the web. It can be easily integrated with other 146 applications. BS Contact is a cross-platform application which is able to work on Windows, 147 Linux, Mac, and mobile platforms. It is able to visualise VRML (Virtual Reality Modelling 148 Language), X3D (Extensible 3D), Collada, and KMZ formats. This application was used 149 widely for various purposes. For example, Vandysheva et al. (2012) have developed a web150 based 3D visualisation prototype in the Russian Federation utilising BS Contact plug-in to 151 represent $3 \mathrm{D}$ volume objects and associated administrative data.

\subsubsection{TerraExplorer}

153 TerraExplorer (www.skylineglobe.com) is a visualisation application for exploring, editing, analysing and publishing photo-realistic 3D environments. One of the TerraExplorer products is Skyline Globe Viewer which provides advanced API capabilities for web-based 3D visualisation applications. In addition to the viewer, there are TerraExplorer Plus and Pro which provides users with capabilities to edit features, add layers, and publish data to be

158 visualised in the Skyline Globe Viewer. Ying, et al. (2012) have developed a web-based 3D

159 visualisation prototype using TerraExplorer for representing land ownership rights and 3D 160 buildings. TerraExplorer meets a number of important requirements such as underground 161 visualisation, supporting various formats, various 3D functions, however, it does not provide users with cross-sectional views which significantly assist users in understanding ownership boundaries.

\subsubsection{XNavigator}


XNavigator (xnavigator.sourceforge.net/doku.php) is an interactive 3D visualisation application for exploring 3D environments and an online viewer for OpenStreetMap Globe

167 (osm-3d.org). The software is built on Java technology and runs on a wide range of 168 platforms. The 3D graphics use OpenGL hardware acceleration and the Java technology 169 allows integration into web pages. XNavigator relies on a client-server architecture and 170 supports Open Geospatial Consortium (OGC) standards. Various OGC services such as Web 171 3D Service (W3DS), Web Map Service (WMS) and Web Feature Service (WFS) are 172 supported. Vandysheva et al. (2011) developed a prototype using XNavigator as a 3D web 173 browser. This application is simple to operate using Java, a wide range of interaction and navigation is possible, and it meets a number of requirements.

\subsection{Comparison of the 3D Visualisation Solutions}

In order to choose an appropriate solution for developing a 3D cadastral visualisation prototype, these options were carefully reviewed and their specifications were studied and

178 finally, they were assessed against the requirements in Table 1. A summary of this comparison is presented in Table 2 .

Table 2. Comparison Table.

\begin{tabular}{lcccccc}
\hline \multirow{2}{*}{ Visualisation Features } & \multicolumn{5}{c}{ Visualisation Solutions } \\
\cline { 2 - 5 } & WebGL & $\begin{array}{c}\text { Google } \\
\text { Earth }\end{array}$ & $\begin{array}{c}\text { NASA } \\
\text { WW }\end{array}$ & $\begin{array}{c}\text { BS } \\
\text { Contact }\end{array}$ & $\begin{array}{c}\text { TerraExplore } \\
\text { r }\end{array}$ & XNavigator \\
\hline Handling Massive Data & No & $\begin{array}{c}\text { Yes } \\
\text { Network } \\
\text { links) }\end{array}$ & Yes & No & Yes & No \\
$\begin{array}{l}\text { Result of Functions and } \\
\text { Queries }\end{array}$ & Yes & $\begin{array}{c}\text { Yes } \\
\text { (only } \\
\text { search) }\end{array}$ & Yes & Yes & Yes & Yes \\
Underground View & Yes & No & No & Yes & Yes & No \\
Cross-section View & No & No & No & No & No & No \\
Measurements (3D) & No & No & No & No & Yes & No \\
$\begin{array}{l}\text { Non-Spatial Data } \\
\text { Visualisation }\end{array}$ & Yes & Yes & Yes & Yes & Yes & Yes \\
Interactivity & Yes & Yes & Yes & Yes & Yes & Yes \\
Levels of Detail & Yes & Yes & Yes & Yes & Yes & Yes \\
$\begin{array}{l}\text { Symbols } \\
\text { Colour, Thickness, Line- } \\
\text { Style }\end{array}$ & Yes & Yes & Yes & Yes & Yes & Yes \\
Labelling & Yes & Yes & Yes & Yes & Yes & Yes \\
Transparency & Yes & Yes & Yes & Yes & Yes & Yes \\
& & & & & Yes
\end{tabular}




\begin{tabular}{|c|c|c|c|c|c|c|}
\hline Tooltips & No & Yes & Yes & No & Yes & Yes \\
\hline Technical Diversity & Weak & Yes & Yes & Yes & Yes & Yes \\
\hline $\begin{array}{l}\text { System Integration and } \\
\text { Interoperability }\end{array}$ & Yes & Yes & Yes & Yes & Yes & Yes \\
\hline Usability & Low & High & Medium & Medium & Medium & Low \\
\hline Platform Independence & $\begin{array}{l}\text { PC, Mac, } \\
\text { Linux, } \\
\text { Android }\end{array}$ & $\begin{array}{l}\text { PC, Mac, } \\
\text { Linux }\end{array}$ & $\begin{array}{c}\text { Platform } \\
\text { Independe } \\
\text { nt } \\
\text { (java } \\
\text { based) }\end{array}$ & $\begin{array}{l}\text { PC, Mac, } \\
\text { Linux, } \\
\text { Mobile }\end{array}$ & Windows & $\begin{array}{c}\text { Platform } \\
\text { Independent } \\
\text { (java based) }\end{array}$ \\
\hline Cost & $\begin{array}{l}\text { Open- } \\
\text { source }\end{array}$ & Freeware & $\begin{array}{l}\text { Open- } \\
\text { source }\end{array}$ & Proprietary & Proprietary & Open-source \\
\hline $\begin{array}{l}\text { Web-based 3D } \\
\text { Visualisation }\end{array}$ & Yes & Yes & Yes & Yes & Yes & Yes \\
\hline Plug-in Free & Yes & No & $\begin{array}{c}\text { Yes } \\
\text { (Java is } \\
\text { required) }\end{array}$ & $\begin{array}{l}\text { No } \\
\text { (X3DOM } \\
\text { is plug-in } \\
\text { free) }\end{array}$ & No & $\begin{array}{c}\text { No } \\
\text { (Java is } \\
\text { required) }\end{array}$ \\
\hline
\end{tabular}

Google Earth and NASA World Wind are rejected as they are unable to represent

182 underground objects. None of the listed solutions have built-in provision for cross-sectional

183 views, however, the extendibility of WebGL and XNavigator, allows development of a cross-

184 section function. The availability of source code is important to flexibility in development of

185 new functions. TerraExplorer and BS Contact are proprietary products and we preferred to

186 work with open-source applications. Therefore, the remaining candidates were WebGL and

187 XNavigator.

188 WebGL is chosen because of its rapid on-going development and better support through 189 its community of users. WebGL can meet users' expectations for better graphics on the web 190 and as a result many web browsers support this technology.

$191 \quad$ However, WebGL has some limitations:

- WebGL cannot render massive datasets. The reason for this is that the supported

- WebGL is designed to run on today's average computer systems. Older computers may not support WebGL due to their graphic card limitations.

WebGL is a low level API for programmers and drawing a simple 3D model such as a cube needs a lot of work. Accordingly, several open-source JavaScript libraries have been

199 developing to simplify the programming of 3D scenes using WebGL technology. They 200 provide a higher level access to the API to make it simple for programming. For instance, 
201 Three.js (threejs.org), SpiderGL (spidergl.org), Kuda (code.google.com/p/kuda), and SceneJS (scenejs.org) are widely used for 3D web-based applications. However, Three.js is the most popular in terms of the number of users who can help fellow developers in their difficulties. Accordingly, Three.js was selected as the high level API for developing our prototype.

\section{Design and Development of the Prototype}

Before describing the development of the prototype, some important issues involving data and users are reviewed. These considerations helped ensure that the prototype was fit for purpose.

\subsection{Data}

It is important to understand what types of data should be represented in a $3 \mathrm{D}$ cadastral application. Cadastral data includes both legal and physical data (Shojaei et al., 2013) and visualisation of these different types of data requires special functionality. Physical data includes walls, roofs, ceilings, doors, windows, etc. They are concrete and are visible. Legal data such as ownership boundaries are conceptual and abstract. Cadastral applications need to be able to represent both physical and legal data independently and to leave no room for ambiguity about the boundary of ownership spaces (Aien et al., 2013b). These legal counterparts can be both bounded and unbounded volumes (Lemmen et al., 2010).

There are many different 3D data formats such as Collada (collada.org), CityGML (www.citygml.org), IFC (Industry Foundation Class) used to define 3D objects. Loading the data into WebGL/Three.js therefore involves finding a match between the formats it understands and the formats which best suit the physical and legal objects.

When direct import is not possible, there are two other approaches to loading data into WebGL in Three.js, namely hard coding and parsing JSON files. Hard coding is the simplest approach and codes of objects are written using Three.js components. This method is not suitable for an application which will load big data. The second approach is using JSON parser. However, JSON format does not support various types of geometry (e.g. lines) and it is limited to some basic 3D models and not big models. We therefore chose the Collada format for direct import of 3D objects. Collada is a widely used 3D file format defined in XML schema to transport 3D models among 3D applications, it provides a partial match to our requirements.

Collada parser, as part of Three.js libraries, is able to push the 3D models into Three.js libraries for rendering. Many others formats can be converted to Collada to be visualised in 
3D. Various data formats for 3D cadastre have been proposed such as LandXML and KML (Shojaei et al., 2012), CityGML (Dsilva, 2009) and IFC (El-Mekawy and Östman, 2012).

We used IFC format in this development as we identified the following drivers in utilising IFC:

- The new popular format among architectural companies is IFC, which is based on Building Information Modelling;

- 3D designs generated by architects in Victoria are often in IFC format;

- It has enough flexibility to geometrically represent complex objects;

Also, other 3D formats have some limitations such as:

- LandXML cannot support objects with complex geometry;

- Although CityGML has a lot of attention in the academic environment, it is barely used in industry;

However, in this paper, there is no insistence to only use IFC format, as we focused only on $3 \mathrm{D}$ visualisation. Therefore, other data formats can be utilised in $3 \mathrm{D}$ cadastres in an appropriate data model.

Many architectural companies create IFC models of buildings using various 3D software products such as Autodesk Revit and ArchiCAD in the 3D design process of developments. Then, they present the proposed 3D models of developments to their clients. After approval by clients, 3D models are converted into 2D plans and delivered to others such as developers, land surveyors, and local governments. Although, 3D models are created in the beginning of land development process, they are typically converted to 2D plans and are not employed in $3 \mathrm{D}$ in the whole process of land development.

El-Mekawy and Östman (2012) have described the deficiencies of IFC for 3D cadastre and suggested extensions to meet cadastral needs. We see IFC as a strong candidate for longterm use in development of a 3D digital cadastre. However, IFC is not supported in WebGL. Therefore, IFC files need to be converted into Collada format to be represented in WebGL. IFC files may not include visual variables (e.g. colour, texture and transparency) and when they are converted to other formats like Collada, all objects will be white and have no transparency. Therefore, a process is required to assign style and change the colour or transparency of the objects for better representation. 
Furthermore, IFC files only comprise physical objects such as walls, windows, slabs and doors. However, legal objects such as lots, easements, and common property are the essential part of a 3D cadastre. These legal objects are not supported by most 3D products. For example, Autodesk Revit only supports physical objects and does not support legal objects. Therefore, in order to have legal objects in IFC files, we used the "Room" component in Autodesk Revit as a substitute for 3D legal objects. Room in Autodesk Revit is defined as a component which is limited to the walls (or user defined boundaries) and ceiling and roof. This component can be used to define the boundary of lots, easements and common property. In order to draw 3D legal objects, as a test case, we employed the subdivision plans of a recent high-rise development to locate the ownership boundaries of the legal objects. By using Autodesk Revit, legal and physical objects associated with the test property were prepared for the prototype.

\subsection{Users}

This prototype can be used by anyone wishing to understand ownership boundaries. This includes the public, property managers, developers, architects, real estate agents, lawyers, land surveyors and registrars. While creating and editing 3D objects on-line is feasible, it is not recommended as it is too slow and too complicated to develop required functions on the web (Shojaei et al., 2013). Therefore, the prototype is designed to provide only a viewing environment, supported by query and analysis features as described below.

\subsection{The 3D Prototype}

This sub-section provides an overview, describes the architecture and functional features and reviews development issues in the prototype design and development phase.

\subsubsection{Functional Overview}

The prototype allows users to search and find developments based on the 2D cadastral parcel address. This would be the usual way to start an exploration and occurs in a browser window. Then, users are able to navigate around the property and see its location and other representing underground objects, we utilised it in the prototype to provide a property overview. 


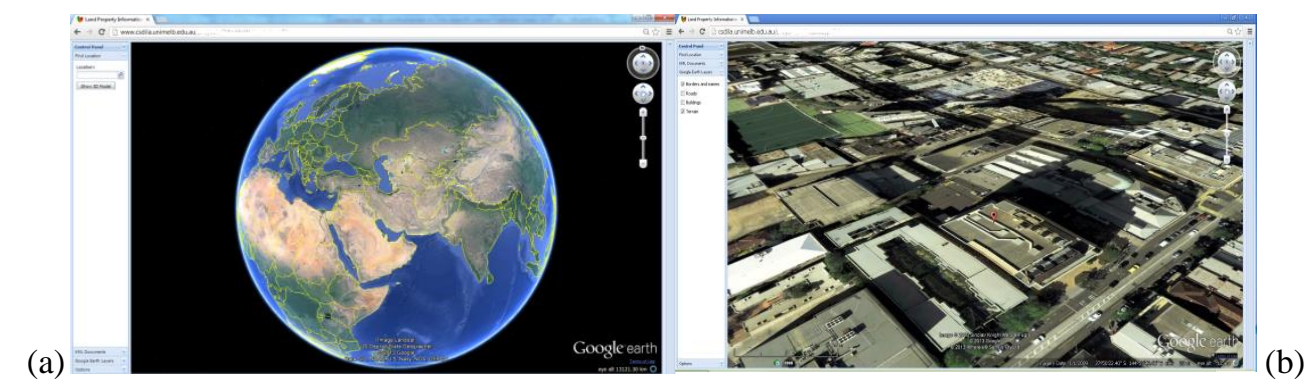

293

Figure 1. (a) The GUI developed using Google Earth API WebGL; (b) Search and find buildings based on the 2D cadastral parcel address.

After that, by clicking a button, "Show 3D Model", a new tab is opened containing the WebGL canvas providing a view of individual buildings on the parcel and associated legal objects (Figure 2). At this stage, the prototype presents just a single parcel at a time because of the data load and processing limitations in WebGL. All the normal navigational functions are present for exploration, and a variety of additional functions have been included. For example, users are able to turn on/off various physical and legal objects to jointly or separately see the building parts and the ownership boundaries. Also, users may measure a distance in 3D or create a cross-section view. Moreover, all existing legal documents such as traditional subdivision plans are accessible as PDF documents in the prototype.

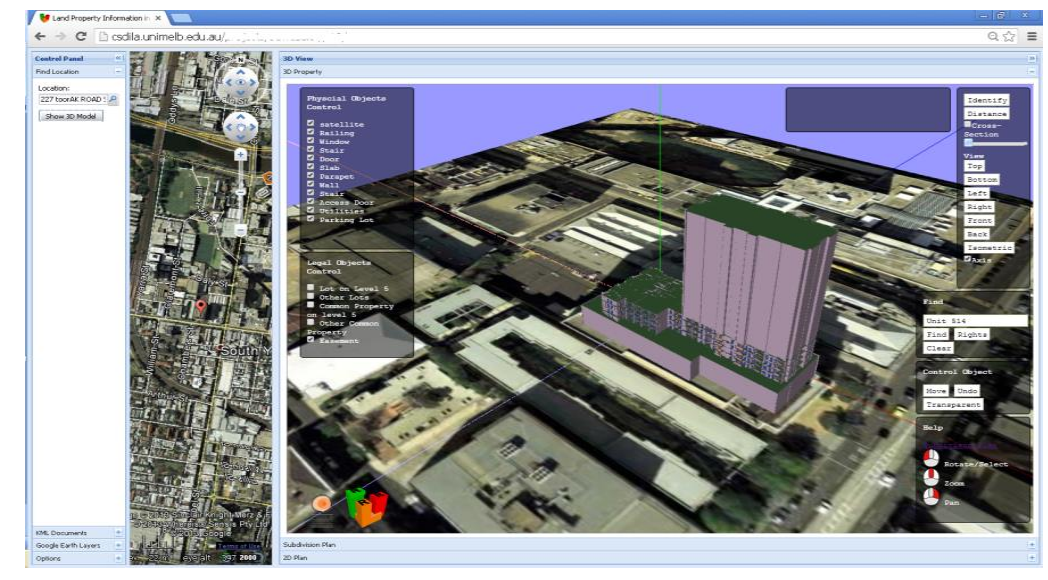

Figure 2. A snapshot of the GUI and WebGL tab.

\subsubsection{Architecture}

To develop these functionalities in the prototype, WebGL and Three.js libraries were employed and an architecture was designed as illustrated in Figure 3. This architecture contains two main functional parts namely a data repository and the GUI (Graphic User Interface) which are explained here further. 


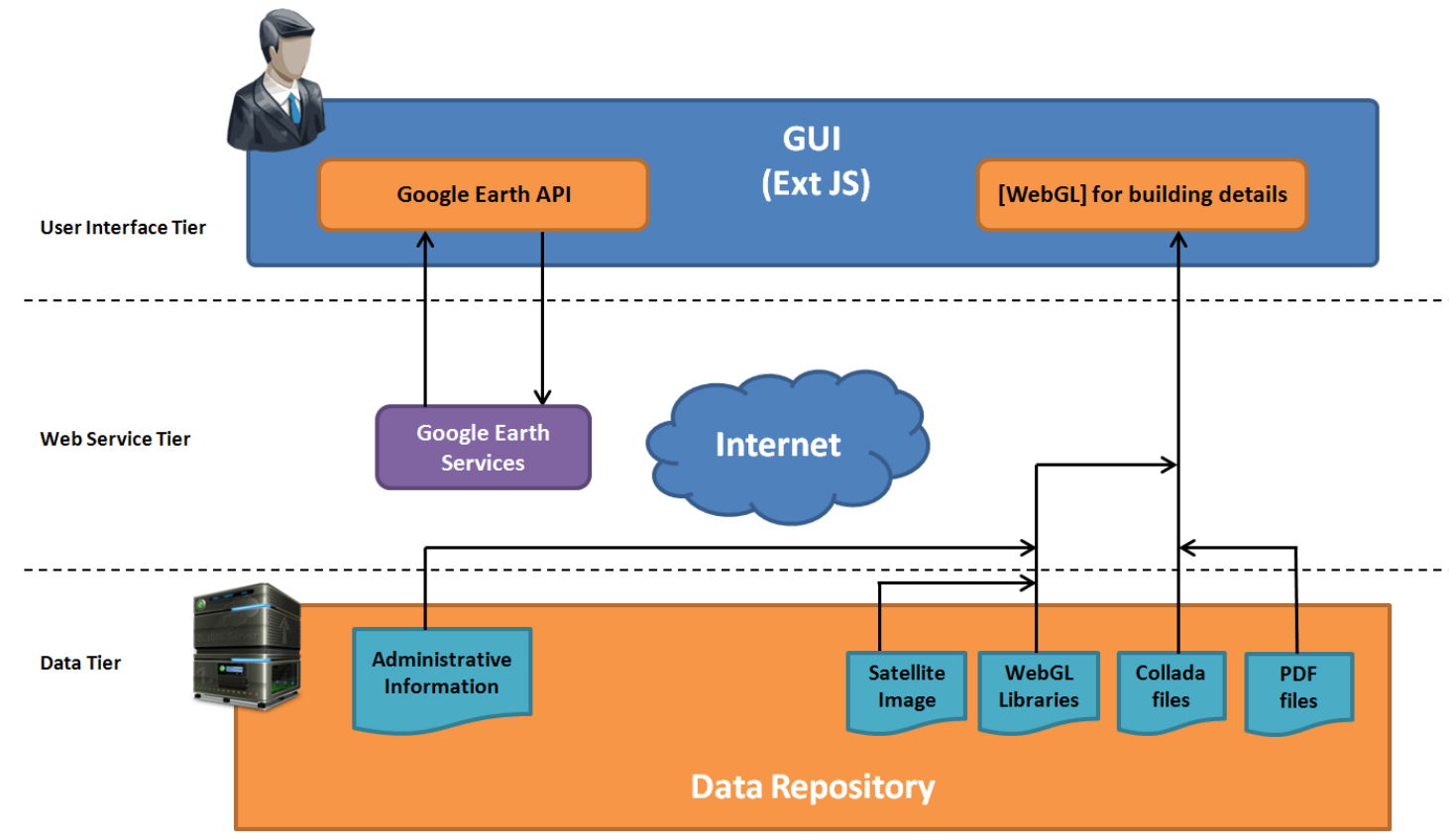

Figure 3. The proposed architecture for design and development of the prototype.

The data repository which is located in the data tier includes 3D models (Collada files), subdivision plans (PDF files), WebGL libraries, a satellite image and administrative information attached to $3 \mathrm{D}$ models in the server. Administrative information includes ownership, plan number and plan permit number. In order to connect administrative information to 3D models, unique IDs were attached to each object in the Collada files.

The GUI, located in the user interface tier, draws 3D models derived from the server. Various technologies were utilised to produce the GUI namely Google Earth API, WebGL technology, HTML 5, JavaScript and Ext JS. The Google Earth API provides users with some initial capabilities such as searching an address and so seeing a parcel in the context of the city. This could be extended to include the DCDB.

Google Earth was embedded in a page using JavaScript. Google Earth API is not opensource, however, some small changes are allowed to customise applications for various needs. For example, layers and objects can be switched on or off. These functions are controlled using the API. In addition, Ext JS was utilised which provides the GUI programmer with customisable frames, buttons, and tabs to build a robust application interface. 
Because of limitations in the Google Earth API (Table 2) WebGL was employed to bring a 3D canvas into the browser. WebGL is able to render 3D models and provides users with the essential functions to explore 3D models. Figure 2 shows snapshots of the GUI. The features of the GUI are described in detail below followed by a review of some development challenges.

\subsubsection{Functional Features}

We developed the following functions using Three.js libraries in the JavaScript development environment.

\section{- Identify Tool}

In order to retrieve information attached to each object in the scene, an Identify tool was developed using a ray tracing approach. By a mouse click on the scene, a hidden line is created from the 3D mouse position to the camera. This line may intersect with many objects on the scene. We find the nearest intersect to the camera and retrieve the information of that object for presentation in the GUI.

- 3D Measurement Tool

To measure distance in $3 \mathrm{D}$, by each click on the screen, 2D mouse position is converted to $3 \mathrm{D}$ position using the ray tracing technique from the camera location to the nearest surface close to the mouse pointer. By using two consecutive 3D positions of mouse clicks, a 3D distance is computed and a line is drawn to show where the measured distance is.

Cross-section tool is used in order to show the internal complexity of buildings. The camera component in Three.js has two clipping planes, namely the near and far clipping planes. The objects which are located in between these planes are rendered. By changing the distance of the near clipping plane from the camera, different cuts through the objects can be viewed.

- Various Views

On the WebGL interface, different camera positions and angles create various views. In addition to free movement the camera can be quickly located at specific angles such as front, back, isometric, top, right, left, top and bottom, relative to the building. 
An ability to query the prototype and to find and identify objects was part of the defined requirements (Section 2). Thus, after entering an attribute of the objects in the search box, objects with this attribute are highlighted. For example, owners can find the lots which they own by entering their names. These lots are not necessarily contiguous, for example the user's apartment, their allocated car park and their common ownership areas can be highlighted using a new colour. Once the query is completed, the original colour is restored.

- Move, Undo, Transparent

In some cases, it is important to move an object (e.g. a lot) from its location and view it in more detail individually. Thus, a tool was developed that allows any highlighted object to be moved to somewhere else in the view. The object can be moved back to the previous position by a simple Undo option.

\section{- Object Control}

There are two sets of lists at the left side of the scene which provides users with check-box control over object visibility. One list relates to built object, the other to legal objects. This allows any combination of physical and legal objects to be viewed.

- Representing Administrative Information

There are two other tabs on the bottom of the page which provide the option to view administrative information such as subdivision plans and associated documents. Users can refer to these for more detail and in order to see the actual legal documents.

\subsubsection{Additional Development Issues}

Other issues had to be resolved in this prototype to increase the usability. - Touch and Click Events

To support mobile devices (e.g. tablet or smartphone using Android), some special functions were added in the prototype. For instance, mobile devices unlike computers do not have pointing devices (e.g. mouse). Therefore, touch events must be implemented to be interpreted in the same way as click events. Adding touch events to the source code offers the ability to interpret finger activity on touch screens (Figure 4). 
(v csdila.unimelb.edu.au/projects/3dwebsite/HHH/q8/model/final.html

Figure 4. A snapshot of the prototype on a mobile platform. Although, several browsers support WebGL on desktop devices, Blackberry and Android systems currently support WebGL on mobile devices.

There are various types of camera components in the Three.js libraries. In order to give the user the most natural form of control over the objects, the upside of the camera should be always towards the top of the screen - buildings do not normally turn upside-down.

- Zoom and Pan

397 Zoom and pan can be difficult to use if poorly designed. For example, the amount of 398 movement should be related to the distance of the camera from the object of interest. We 399 typically want finer movements when closer. For example, if a camera is 100 meters from 400 objects, by rotating the wheel of the mouse we can reduce this distance. However, this 401 distance should be reduced more slowly when the objects are very close to the camera. The 402 same thing is applicable for pan. When objects are far from the camera, pan speed should be 403 high and vice versa. This provides smoothness in visualisation applications. Therefore, the 404 source code in the Three.js libraries was changed to provide users with more smoothness in 405 the prototype by changing the zoom and pan speed dynamically. 


\subsection{Case-study}

We chose a recently completed multi-story building (Figure 2) as a case study for the evaluation process. This was a good test case because of the complexity of the building and the availability of required data. This building is located in Melbourne, Australia and it includes 400 lots on 28 levels and six common property areas. It is a residential building as well as having some commercial subdivisions. The IFC file of the building was drawn from architectural plans and the subdivision documents of this development were provided by the associated surveying company to allow creation of legal objects.

We used Autodesk Revit to prepare the data as discussed in Section 4.1. Then, the IFC file, including physical and legal objects, was created. Later, Blender was used to convert the IFC file into Collada. Blender itself does not support importing and exporting IFC files, but a plug in (ifcopenshell.org/ifcblender.html) was available to provide this functionality. However, this did not convert any material information such as surface colours. Therefore, colour, transparency and texture were added to the 3D building manually. In the next step, the 3D model was exported to the Collada format. The Collada file was edited in a text editor to include IDs linking the legal information to the 3D model. Then, the 3D model was copied to the server to be retrieved in the prototype.

\section{Evaluation}

We used the prototyping approach (Kotonya and Sommerville, 1998) to quickly and easily assess the usability of the developed prototype. To do this, an online questionnaire was designed and administered to a group of professional users. Twenty-four specialists were invited to six demonstration sessions to evaluate the prototype and fill in the questionnaire. We selected participants who are intimately involved in the processes of development of high-rise buildings. All were from Victoria, Australia, as the case study is in this state and legislation and regulations in Victoria are different from other states in Australia. A summary of the participants in the evaluation phase is presented in Table 3.

Table 3. The list of participants and their expertise in the evaluation of the prototype.

\begin{tabular}{lc}
\hline Specialists & Number of Participants \\
\hline Land Surveyors & 10 \\
Land Registrars & 8 \\
City Managers (Council) & 5 \\
Building Managers (Owners Corporation) & 1 \\
\hline
\end{tabular}

At each session, we gave the subdivision plan of the case study to the participants and we asked them to read and understand the legal objects and ownership boundaries (approximately 5 minutes). Then, the case-study was presented in the prototype (5 minutes). 
Later, the interactive capabilities such as search, identify, cross-section, measurements and navigation were presented (10 minutes). We then asked the participants if they are interested in working with the prototype (5 minutes) and to fill in a questionnaire later.

The questionnaire included 37 statements and questions to evaluate the functionality, 440 usability and efficiency of the prototype. A selection of statements is presented in Table 4 in 441 each case the respondents were asked to record their agreement with the statement on a five 442 point scale (Likert Scale) ranging from strongly disagree (1) to strongly agree (5). The others 443 statements are not reported here as they used a different response type and do not form part of 444 this evaluation.

Table 4. Key questions for evaluating the prototype in the questionnaire

\begin{tabular}{|c|c|c|}
\hline Category & $\begin{array}{l}\text { Question } \\
\text { No. }\end{array}$ & Question \\
\hline \multirow{12}{*}{ 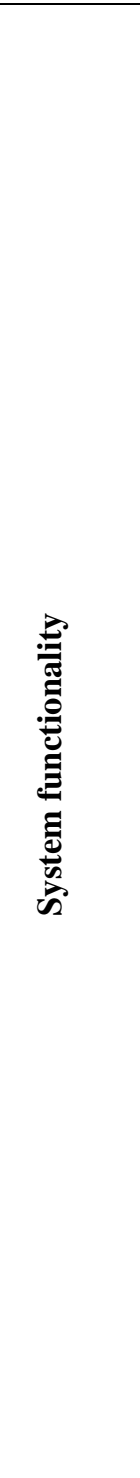 } & 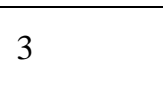 & $\begin{array}{l}\text { I found this 3D visualisation prototype more useful than 2D plans (e.g. architectural } \\
\text { plans, subdivision plans, etc) for understanding ownership boundaries. }\end{array}$ \\
\hline & 4 & $\begin{array}{l}\text { Integration of physical (walls, doors, ceilings, and floors) and legal objects (lots, } \\
\text { easements, common property) in the 3D visualisation prototype facilitates } \\
\text { understanding of ownership boundaries. }\end{array}$ \\
\hline & 6 & $\begin{array}{l}\text { Visualising some physical building components such as slabs and walls which are } \\
\text { considered as common property (shared areas) may increase the complexity of a 3D } \\
\text { model; therefore a simpler model without them, is preferred. }\end{array}$ \\
\hline & 7 & $\begin{array}{l}\text { Utilising such 3D web-based visualisation prototypes will improve communication of } \\
\text { 3D cadastral data among various users. }\end{array}$ \\
\hline & 8 & Utilising such prototypes will improve managing of ownership rights. \\
\hline & 11 & $\begin{array}{l}\text { The 3D presentation of property information is effective in helping me complete my } \\
\text { tasks. }\end{array}$ \\
\hline & 12 & $\begin{array}{l}\text { How satisfied are you with this prototype as a way of presenting 3D property } \\
\text { information (e.g. underground lots) and the available functions? Please include any } \\
\text { comments regarding your level of satisfaction. }\end{array}$ \\
\hline & 13 & I believe I quickly became more productive when using this prototype. \\
\hline & 14 & $\begin{array}{l}\text { I can see that this prototype would potentially contribute to improving productivity in } \\
\text { my daily tasks. }\end{array}$ \\
\hline & 15 & $\begin{array}{l}\text { I would like to see this } 3 \mathrm{D} \text { visualisation prototype implemented for decision making } \\
\text { processes in my organisation. }\end{array}$ \\
\hline & 16 & $\begin{array}{l}\text { A web-based visualisation application is more effective than a desktop-based } \\
\text { application in my tasks. }\end{array}$ \\
\hline & 17 & $\begin{array}{l}\text { Not needing to install a plug-in is beneficial from a security and convenience point of } \\
\text { view. }\end{array}$ \\
\hline
\end{tabular}




22
I feel comfortable using this prototype.
The information (such as subdivision plans, on-screen messages, and other
documentation) provided with this prototype is clear.

446 The System Usability Scale (SUS) method (Brooke, 1996) was used for usability

447 evaluation. For efficiency evaluation, questions regarding the time and cost of 3D

448 representation of cadastral data were asked. As there were different types of users in the

449 evaluation process, we could not combine the results; and findings for each category of users

450 are presented separately. The results are summarised in Table 5. 


\begin{tabular}{|c|c|c|c|c|c|c|}
\hline $\begin{array}{l}\text { Question } \\
\text { No. }\end{array}$ & Discussion & $\begin{array}{l}\text { Land } \\
\text { Surveyors }\end{array}$ & $\begin{array}{c}\text { Building } \\
\text { Managers }\end{array}$ & $\begin{array}{c}\text { Land } \\
\text { Registrars }\end{array}$ & $\begin{array}{c}\text { City } \\
\text { Managers } \\
\text { (Council) }\end{array}$ & $\begin{array}{l}\text { Overall } \\
\text { Average }\end{array}$ \\
\hline 3 & $\begin{array}{l}\text { It seems that city managers still prefer to work with paper-based plans. The reason is } \\
\text { they are very familiar with interpreting ownership boundaries in subdivision plans. }\end{array}$ & 4.4 & 5 & 3.6 & 3.4 & 4 \\
\hline 4 & $\begin{array}{l}\text { All the groups preferred this integration as it facilitates interpreting of ownership } \\
\text { boundaries. }\end{array}$ & 4.6 & 5 & 3.8 & 4.2 & 4.3 \\
\hline 6 & Very few people felt that they preferred a simpler model without shared areas. & 2.8 & 1 & 2.4 & 2 & 2.4 \\
\hline 7 & They would like to have a 3D web-based visualisation application. & 3.7 & 5 & 4 & 4 & 3.9 \\
\hline 8 & $\begin{array}{l}\text { Most of the participants agreed with this. However, the functionality of the } \\
\text { application is very important. }\end{array}$ & 4 & 5 & 3.5 & 3.2 & 3.7 \\
\hline 11 & They confirmed that this prototype can help them in their tasks. & 3.4 & 5 & 3.3 & 3.4 & 3.4 \\
\hline 12 & The participants were mostly satisfied with this prototype. & 4 & 5 & 3.9 & 3.6 & 3.9 \\
\hline 13 & $\begin{array}{l}\text { The city managers raised some issues regarding the performance and functionality. } \\
\text { They have other types of requirements such as energy usages and shadow analysis. }\end{array}$ & 3.1 & 5 & 3.2 & 2.5 & 3.1 \\
\hline 14 & $\begin{array}{l}\text { They accepted that this prototype would potentially contribute to improving } \\
\text { productivity. }\end{array}$ & 3.6 & 5 & 3.5 & 3.6 & 3.6 \\
\hline 15 & $\begin{array}{l}\text { Most of the participants agreed to have this prototype implemented in their } \\
\text { organisations. }\end{array}$ & 4.1 & 5 & 3.3 & 3 & 3.6 \\
\hline 16 & $\begin{array}{l}\text { In some tasks, such as data creation and updating, desktop based applications are } \\
\text { more efficient. }\end{array}$ & 3.8 & 5 & 3.6 & 3 & 3.6 \\
\hline 17 & They agreed the benefits of plug-ins free applications. & 3.9 & 3 & 4 & 4 & 3.9 \\
\hline 22 & They feel comfortable with the prototype. & 3.6 & 4 & 3.4 & 3.5 & 3.6 \\
\hline 23 & Nearly all approved this prototype as a user friendly application. & 3.8 & 4 & 3.4 & 3.4 & 3.6 \\
\hline 24 & The information attached to the prototype was clear to understand. & 3.7 & 3 & 3.4 & 3.5 & 3.6 \\
\hline 25 & They found this prototype very easy to use. & 3.8 & 4 & 2.8 & 3 & 3.4 \\
\hline 26 & $\begin{array}{l}\text { The participants from council were expecting more functions according to their } \\
\text { needs. }\end{array}$ & 3.8 & 4 & 3.4 & 2.5 & 3.5 \\
\hline 27 & $\begin{array}{l}\text { Most of the participants liked the interface. However, there is room for improvement. } \\
\text { Very few respondents felt that they needed the support of a technical person to be }\end{array}$ & 3.8 & 4 & 3.4 & 3 & 3.5 \\
\hline 29 & $\begin{array}{l}\text { able to use this prototype (The rates are showing their disagreement with the } \\
\text { statement). }\end{array}$ & 2.8 & 3 & 3 & 2.4 & 2.8 \\
\hline 36 & $\begin{array}{l}\text { Nearly all accepted using this prototype will result in saving time for understanding } \\
\text { ownership rights. }\end{array}$ & 3.8 & 5 & 3.8 & 3.4 & 3.8 \\
\hline 37 & $\begin{array}{l}\text { Most of the participants accepted using this prototype will result in saving cost for } \\
\text { understanding ownership rights. }\end{array}$ & 3.9 & 5 & 3.6 & 2.6 & 3.6 \\
\hline
\end{tabular}


The scores for Questions 3, 7 and 12, indicate that the prototype successfully met user expectations. In addition, most of the participants mentioned such an application will save time in understanding ownership rights. However, based on Question 6, many participants preferred to present all the spaces including all common property areas. According to the received comments, the following aspects need to be further considered:

- Data

- All legal boundaries and relevant definitions need to be shown. There are a number of notations that are legally required in describing boundaries. For example, official measurements for parcel boundaries such as bearings and distances need to be added;

- Most buildings do not have BIM files. Data capture and maintenance is a significant issue;

- Data security and property right guarantee must be considered.

- The costs associated with building 3D models are initially high. Cost savings would emerge a long time after a 3D approach to cadastral management was introduced; and

○ Representing unbounded volumes, such as height or depth limitations, has not been considered.

- Functionality

○ Improve the response time;

○ Improve the cross-section tool; and

○ More key-in searching and filtering for lot and ownership information.

- User interface

- Reduce the number of menu options and improve the interface using menu bars and split screen view;

- Develop a help page for users; and

○ Larger text to make it more legible, consideration of screen size should be incorporated for user interaction.

\section{Conclusion}

In this study, some 3D visualisation solutions were assessed against the requirements of 3D cadastral visualisation. For the first time, we investigated the capability of using WebGL technology in 3D cadastre by developing a 3D web-based cadastral visualisation prototype. In addition, several tools were developed for 3D cadastre in Three.js libraries. The developed 
prototype is capable of visualising both physical and legal objects to convey a clear image of ownership boundaries. Furthermore, an approach was developed for storing 3D legal objects in IFC format.

The developed prototype was tested and evaluated against user requirements and feedback was received. The overall feedback was positive and valuable comments about the functionality of the prototype will be considered in future work. There were insufficient building mangers to properly assess this category of users. Other potential users who are involved in land development processes, such as developers, architects and lawyers, can be included in future analysis.

According to the comments, the lack of a $3 \mathrm{D}$ visualisation application for representing ownership boundaries is evident and the industry is keen to find a solution. WebGL was found to have high potential, given further development, for managing properties in 3D.

\section{Acknowledgments}

This research project is an ARC Linkage Project (Land and Property Information in 3D) funded by the Australian Research Council (ARC) in collaboration with the Centre for Spatial Data Infrastructures and Land Administration, the University of Melbourne, Land

Victoria (VIC), Land and Property Management Authority (NSW), Australian Research views expressed in this paper are authors' and do not essentially reflect any of these parties' points of view.

\section{References}

ADITYA, T., ISWANTO, F., WIRAWAN, A. \& LAKSONO, D. P. 2011. 3D Cadastre Web Map: Prospects and Developments. 2nd International Workshop on 3D Cadastres. Delft, the Netherlands.

AIEN, A., KALANTARI, M., RAJABIFARD, A., WILLIAMSON, I. \& BENNETT, R. 2013a. Utilising data modelling to understand the structure of 3D cadastres. Journal of Spatial Science, 1-20.

AIEN, A., KALANTARI, M., RAJABIFARD, A., WILLIAMSON, I. \& WALLACE, J. 2013b. Towards Integration of 3D Legal and Physical Objects in Cadastral Data Models. Land Use Policy, 35, 140-154.

AIEN, A., RAJABIFARD, A., KALANTARI, M., WILLIAMSON, I. \& SHOJAEI, D. 2011. 3D Cadastre in Victoria Australia. GIM International. 
BROOKE, J. 1996. SUS: A Quick and Dirty Usability Scale. In: JORDAN, P. W., WEERDMEESTER, B., THOMAS, A. \& MCLELLAND, I. L. (eds.) Usability evaluation in industry. Taylor and Francis.

COORS, V. 2003. 3D-GIS in networking environments. Computers, Environment and Urban Systems, 27, 345-357.

DIMOVSKI, V., BUNDALESKA-PECALEVSKA, M., CUBRINOSKI, A. \& LAZOROSKA, T. 2011. WEB Portal for Dissemination of Spatial Data and Services for the Needs of the Agency for Real Estate Cadastre of the Republic of Macedonia (AREC). 2nd International Workshop on 3D Cadastres. Delft, the Netherlands.

DSILVA, M. G. 2009. A Feasibility Study on CityGML for Cadastral Purposes. Masters Thesis, Eindhoven University of Technology.

EL-MEKAWY, M. \& ÖSTMAN, A. 2012. Feasibility of Building Information Models for 3D Cadastre in Unified City Models. IGI Global.

ELIZAROVA, G., SAPELNIKOV, S., VANDYSHEVA, N., PAKHOMOV, S., OOSTEROM, P. V., VRIES, M. D., STOTER, J., PLOEGER, H., SPIERING, B., WOUTERS, R., HOOGEVEEN, A. \& PENKOV, V. 2012. Russian-Dutch Project "3D Cadastre Modelling in Russia". 3rd International Workshop on 3D Cadastres: Developments and Practices. Shenzhen, China.

FRÉDÉRICQUE, B., RAYMOND, K. \& VAN PROOIJEN, K. 2011. 3D GIS as Applied to Cadastre - A Benchmark of Today's Capabilities. FIG Working Week 2011. Marrakech, Morocco.

GUO, R., LI, L., HE, B., LUO, P., YING, S., ZHAO, Z. \& JIANG, R. 2011. 3D Cadastre in China - a Case Study in Shenzhen City. 2nd International Workshop on 3D Cadastres. Delft, the Netherlands

HASSAN, M. I. \& ABDUL RAHMAN, A. 2010. Malaysian Integrated 3D Cadastre. XXIV International FIG Congress. Sydney, Australia.

JARROUSH, J. \& EVEN-TZUR, G. 2004. Constructive Solid Geometry as the Basis of 3D Future Cadastre. FIG Working Week 2004. Athens, Greece.

KOTONYA, G. \& SOMMERVILLE, I. 1998. Requirements Engineering: Processes and Techniques, John Wiley \& Sons Ltd.

LEMMEN, C., VAN OOSTEROM, P., THOMPSON, R., HESPANHA, J. \& UITERMARK, H. 2010. The Modelling of Spatial Units (Parcels) in the Land Administration Domain Model (LADM). FIG Congress 2010. Sydney, Australia.

PAULSSON, J. \& PAASCH, J. M. 2011. 3D Property Research - a Survey of the Occurrence of Legal Topics in Publications 2nd International Workshop on 3D Cadastres. Delft, the Netherlands.

PEREIRA, K. 2013. Water Simulation on WebGL and Three.js. Bachelor of Science, The University of Southern Mississippi.

POULIOT, J. 2011. Visualization, distribution and delivery of 3D parcels. 2nd International Workshop on 3D Cadastres. Delft, The Netherlands.

SHOJAEI, D., KALANTARI, M., BISHOP, I. D., RAJABIFARD, A. \& AIEN, A. 2013. Visualization requirements for 3D cadastral systems. Computers, Environment and Urban Systems, 41, 39-54.

SHOJAEI, D., RAJABIFARD, A., KALANTARI, M., BISHOP, I. D. \& AIEN, A. 2012. Development of a 3D ePlan/LandXML Visualisation System in Australia. 3rd International Workshop on 3D Cadastres: Developments and Practices. Shenzhen, China.

STOTER, J. \& SALZMANN, M. 2003. Towards a 3D cadastre: where do cadastral needs and technical possibilities meet? Computers, Environment and Urban Systems, 27, 395-410.

STOTER, J. E. 2004. 3D Cadastre. PhD Thesis, TU Delft.

STOTER, J. E. \& ZLATANOVA, S. 2003. Visualisation and editing of 3D objects organised in a DBMS. Proceedings of the EuroSDR Com V. Workshop on Visualisation and Rendering. Enschede, The Netherlands.

VAN OOSTEROM, P. 2012. Summary of the Third International FIG Workshop on 3D Cadastres Developments and practices. Third International FIG Workshop on 3D Cadastres Developments and practices. Shenzhen, China.

VAN OOSTEROM, P. 2013. Research and development in 3D cadastres. Computers, Environment and Urban Systems, 40, 1-6. 
VANDYSHEVA, N., IVANOV, A., PAKHOMOV, S., SPIERING, B., STOTER, J., ZLATANOVA, S. \& VAN OOSTEROM, P. 2011. Design of the 3D Cadastre Model and Development of the Prototype in the Russian Federation. 2nd International Workshop on 3D Cadastres. Delft, the Netherlands.

VANDYSHEVA, N., SAPELNIKOV, S., VAN OOSTEROM, P., DE VRIES, M., SPIERING, B., WOUTERS, R., HOGEVEEN, A. \& PENKOV, V. 2012. The 3D Cadastre Prototype and Pilot in the Russian Federation. FIG Working Week 2012. Rome, Italy.

YING, S., GUO, R., LI, L. \& HE, B. 2012. Application of 3D GIS to 3D Cadastre in Urban Environment. 3rd International Workshop on 3D Cadastres: Developments and Practices. Shenzhen, China. 